\title{
Ring-Opening Polymerization of Aromatic 6-Membered Cyclic Disulfide and Characterization of the Polymer
}

\author{
By Hidenobu ISHIDA, Atsushi KISANUKI, and Kiyoshi ENDO*
}

\begin{abstract}
Synthesis and characterization of polymers obtained from polymerization of 1,4-dihydro-2,3-benzodithine (XDS) were investigated. The polymerization of XDS proceeded at reaction temperatures above the melting points of XDS to give polymers, and the molecular weight, which determined by GPC was high. From the structural analysis of poly(XDS), the polymer was found to have cyclic structure, in contrast to their linear polymer (poly(XDS-XDT) obtained from the polymerization of XDS in the presence of chain transfer thiol compounds such as $\alpha, \alpha^{\prime}$-mercapto- $o$-xylene (XDT). From TGA and DSC measurements, poly(XDS) with benzene rings in the main chain is more thermal stable than the polymer obtained from the polymerization of 1,2-dithiane (DT). From dynamic viscoelastic measurements, poly(XDS) showed a rubbery plateau under the molten state even though poly(XDS) has no crosslinking system. The difference in solubility between poly(XDS) and poly(XDS-XDT) was also observed. On the basis of the polymer characterizations, it may be concluded that the poly(XDS) obtained from thermal ring-opening polymerization of XDS includes a polycatenane structure.

KEY WORDS: Ring-Opening Polymerization / 1,4-Dihydro-2,3-Benzodithine / Cyclic Polymer / Polycatenane Structure / Cyclic

Disulfides / Thermal Decomposition /
\end{abstract}

Recently, much attention has been paid to topologically unique macromolecules containing a single cyclic and multicyclic polymer unit from the viewpoints of not only their distinctive properties that is different from linear polymers, but also elements of architecturally complex polymers and interlocked macromolecules such as polyrotaxanes and polycatenanes. ${ }^{1-11}$ Many studies on synthesis of cyclic polymers in the polymerizations have been also reported. ${ }^{12-26}$ Although efficient synthesis of rotaxanes and catenanes have been achieved, ${ }^{27-37}$ a high molecular weight polycatenane which consists of only ring components has not been synthesized. Recently, Takata et al. reported that the Diels-Alder polymerization of [2]catenane bearing diene and dienophile moieties on each ring afforded a "bridged polycatenane" with a poly[2]catenane skeleton. $^{38}$

Many approaches have been reported to prepare polymers containing disulfide linkages in the main chain. ${ }^{39-46}$ Ringopening polymerization of cyclic disulfide compounds is one method for synthesizing such polymers. Although many studies on the polymerizations of cyclic disulfides were reported since the second half of the $1940 \mathrm{~s},{ }^{39,40}$ the detailed structural analyses and characterizations of the resulting polymers have not been investigated for a long time. Recently, we reported the thermal polymerization of 1,2-dithiane (DT) and detailed structural analyses and characterizations of the resulting polymers. From analyses of the polymer, the cyclic structure was formed mainly by a backbiting reaction of propagating species. $^{44-46}$

We also reported that a polycatenane structure composed of interlocking system by entanglements with cyclic polymers was formed during the thermal polymerization of DT in bulk, which was concluded by the results of the solubility and the photodecomposition behavior of the resulting polymer, the polymerization in the presence of other cyclic polymers, and the thermal and physical properties of the polymers (Scheme 1). ${ }^{45,46}$

The thermal polymerization of aromatic cyclic disulfides without initiators was not investigated. If benzene rings are introduced in the main chain, it is expected that more rigid polymers will be synthesized in comparison with aliphatic disulfide polymers. In this article, we synthesized $o$-xylenedisulfide (XDS), i.e., 1,4-dihydro-2,3-benzodithiine, a six-membered cyclic disulfide containing a benzene ring, and the polymerization of XDS was examined to elucidate the structure of the polymer.

\section{EXPERIMENTAL}

\section{Materials}

$o$-Xylene (Wako Pure Chemical), N-bromosuccinimide (NBS) (Wako Pure Chemical), thiourea (Wako Pure Chemical) and poly(ethylene glycol) (PEG: $M_{\mathrm{n}}=1000$, ALDRICH) were used without further purification.

$\alpha, \alpha^{\prime}$-Dibromo- $o$-xylene was synthesized from $o$-xylene in the following procedure. ${ }^{47} o$-Xylene $(25.06 \mathrm{~g}, 236 \mathrm{mmol})$ and NBS $(84.12 \mathrm{~g}, 473 \mathrm{mmol})$ were dissolved in $250 \mathrm{~mL}$ of cyclohexane containing AIBN (2.1 g, $13 \mathrm{mmol}$ ), and the mixture was heated at reflux for $12 \mathrm{~h}$, cooled, and all floating materials were filtered off. After the solution was extracted with chloroform, the organic layer was washed with water several times, and dried over anhydrous sodium carbonate. After evaporating the solvents, the resulting pale yellow oil was recrystallized from

Department of Applied Chemistry \& Bioengineering Graduate School of Engineering, Osaka City University, Sugimoto, Sumiyoshi-ku, Osaka 558-8585, Japan

*To whom correspondence should be addressed (Tel: +81-6-6605-2697, Fax: +81-6-6605-2697, E-mail: endo@a-chem.eng.osaka-cu.ac.jp). 


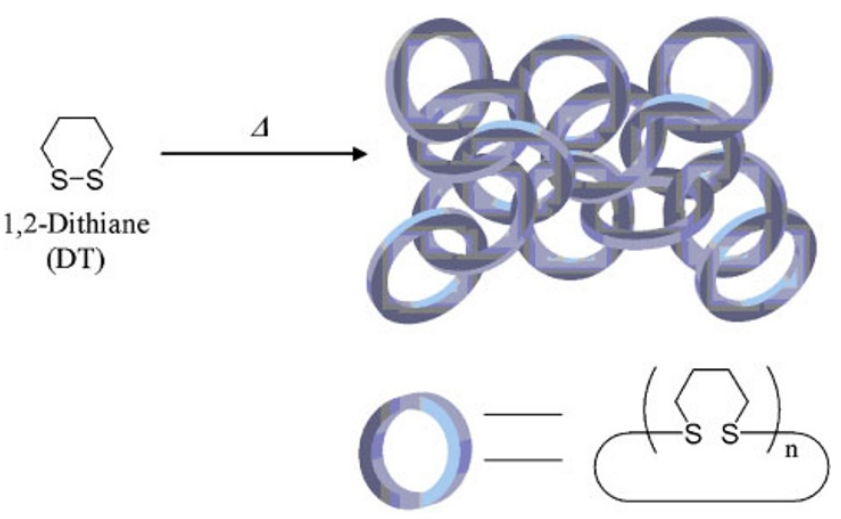

Scheme 1. Synthesis of Polycatenane by Polymerization of DT.

cold methanol using a dry ice/methanol bath. A white precipitate was obtained in a $37 \%$ yield: ${ }^{1} \mathrm{H}$ NMR $\left(\mathrm{CDCl}_{3}\right.$, $400 \mathrm{MHz}) \delta(\mathrm{ppm}) 4.65\left(\mathrm{~s}, \mathrm{Br}-\mathrm{CH}_{2}-\mathrm{Ph}, 4 \mathrm{H}\right), 7.24-7.31(\mathrm{~m}$, phenyl-H3, -H6, 2H), 7.33-7.36 (m, phenyl-H4, - H5, 2H); ${ }^{13} \mathrm{C} \mathrm{NMR}\left(\mathrm{CDCl}_{3}, 100 \mathrm{MHz}\right) \delta(\mathrm{ppm}) 29.9\left(\mathrm{Br}-\mathrm{CH}_{2}-\mathrm{Ph}\right), 129.3$ (phenyl-C4, -C5), 131.0 (phenyl-C3, -C6), 136.5 (phenyl- $C 1$, -C2); m.p. 92-94 (lit. ${ }^{48} 92-93^{\circ} \mathrm{C}$ ).

$\alpha, \alpha^{\prime}$-Mercapto- $o$-xylene (XDT) was synthesized from $\alpha, \alpha^{\prime}$ dibromo- $o$-xylene in the following procedure. ${ }^{49} \alpha, \alpha^{\prime}$-Dibromo$o$-xylene $(30.02 \mathrm{~g}, 102.1 \mathrm{mmol})$ and thiourea $(17.40 \mathrm{~g}$, $228.6 \mathrm{mmol}$ ) were dissolved in $230 \mathrm{~mL}$ of ethanol and heated at reflux for $3 \mathrm{~h}$. A white product was formed, and filtered off. The product was added to an aqueous solution of $\mathrm{NaOH}(10 \mathrm{~g}$, $0.25 \mathrm{~mol}$ ) in $100 \mathrm{~mL}$ water. After refluxing for $2 \mathrm{~h}$, the mixture was neutralized with a dilute $\mathrm{H}_{2} \mathrm{SO}_{4}$ aqueous solution $(5 \mathrm{~mL} /$ $35 \mathrm{~mL}$ ). The solution was extracted with chloroform. The organic layer was washed with water several times, and dried over anhydrous sodium carbonate. After evaporating the solvents, the resulting off-white oil was recrystallized from cold methanol using dry ice/methanol. A white precipitate was obtained in a $91 \%$ yield, m.p. $44-45^{\circ} \mathrm{C}$ (lit. ${ }^{50}$ m.p. $44{ }^{\circ} \mathrm{C}$ ). ${ }^{1} \mathrm{H} \mathrm{NMR}\left(\mathrm{CDCl}_{3}, 400 \mathrm{MHz}\right) \delta(\mathrm{ppm}) 1.83,1.85,1.87$ (t, HS$\mathrm{CH}_{2}-\mathrm{Ph}, 2 \mathrm{H}$ ), 3.84, 3.86 (d, HS-CH2 $-\mathrm{Ph}, 4 \mathrm{H}$ ), 7.20-7.22 (m, phenyl-H3, -H6, 2H), 7.26-7.28 (m, phenyl-H4, -H5, 2H); ${ }^{13} \mathrm{C} \mathrm{NMR}\left(\mathrm{CDCl}_{3}, 100 \mathrm{MHz}\right) \delta(\mathrm{ppm}) 25.9\left(\mathrm{HS}-\mathrm{CH}_{2}-\mathrm{Ph}\right)$, 127.7 (phenyl-C4, -C5), 129.6 (phenyl-C3, -C6), 138.5 (phenyl- $C 1,-C 2$ ).

1,4-Dihydro-2,3-benzodithiine (XDS) was synthesized from $\alpha, \alpha^{\prime}$-mercapto-o-xylene in the following procedure. ${ }^{51}$ Concentrated hydrochloric acid $(1 \mathrm{~mL})$ was added to a dimethyl sulfoxide solution $(25 \mathrm{~mL})$ containing XDT $(0.85 \mathrm{~g}, 4.99$ $\mathrm{mmol})$. The solution was stirred at room temperature for $24 \mathrm{~h}$, and poured into a large amount of ice-water with vigorous stirring, and extracted with chloroform. The organic layer was washed with water several times, and dried over anhydrous sodium carbonate. The product was concentrated in vacuum to remove the solvent, yielding XDS as pale yellow oil. The XDS was purified by recrystallization from diethyl ether and $n$ hexane several times to remove contaminants such as XDT, oligomers and polymers completely. A white precipitate was obtained in a $30 \%$ yield: m.p. $76.6-77.7^{\circ} \mathrm{C}$ (lit. m.p. $77^{\circ} \mathrm{C}^{52}$ );
${ }^{1} \mathrm{H}$ NMR $\left(\mathrm{CDCl}_{3}, 400 \mathrm{MHz}\right) \delta(\mathrm{ppm}) 4.07$ (s, S-CH$\left.-\mathrm{Ph}, 4 \mathrm{H}\right)$, 7.07-7.10 (m, phenyl-H3, -H6, 2H), 7.15-7.19 (m, phenyl- $H 4$, $-H 5,2 \mathrm{H}) ;{ }^{13} \mathrm{C} \mathrm{NMR}\left(\mathrm{CDCl}_{3}, 100 \mathrm{MHz}\right) \delta(\mathrm{ppm}) 34.5\left(\mathrm{~S}_{-} \mathrm{CH}_{2}-\right.$ $\mathrm{Ph}$ ), 126.8 (phenyl-C4, -C5), 130.1 (phenyl-C3, -C6), 132.8 (phenyl- $C 1,-C 2$ ).

Cyclic poly(oxyethylene) was synthesized from commercially available $\alpha, \omega$-hydroxy-terminated poly(oxyethylene) according to the literature. ${ }^{53}$ The product was characterized as follows: m.p. $47.9-48.9{ }^{\circ} \mathrm{C} ;{ }^{13} \mathrm{C} \mathrm{NMR}\left(\mathrm{CDCl}_{3}, 100 \mathrm{MHz}\right)$ $\delta(\mathrm{ppm}) 66.8\left(\mathrm{CH}_{2}-\mathrm{O}-\mathrm{CH}_{2}-\mathrm{O}\right), 70.3-70.7\left(\mathrm{CH}_{2}-\mathrm{CH}_{2}-\mathrm{O}\right), 95.5$ $\left(\mathrm{O}-\mathrm{CH}_{2}-\mathrm{O}\right) ;\left(M_{\mathrm{n}}=825, M_{\mathrm{w}} / M_{\mathrm{n}}=1.01\right.$ (determined by $\mathrm{GPC}$ in THF).

\section{Polymerization Procedure}

Polymerization was carried out in a sealed glass tube. After the required amounts of reagents were charged, the tube was degassed and then sealed under high vacuum. After polymerization at constant temperature for a given time in a thermostat, the contents in the tube were poured into a large amount of methanol or $n$-hexane to precipitate the polymer. The polymer was washed well with a large amount of acetone, $n$-hexane or methanol, and dried in vacuo at room temperature overnight. The isolated polymer yield was determined gravimetrically.

\section{Degradation of Polymers}

Photodecomposition of polymers was carried out in $\mathrm{THF}$ $(0.02 \mathrm{wt} \%)$ solution at room temperature for a given time under UV irradiation using a high-pressure mercury lamp (Toshiba SHL-100-2, $100 \mathrm{~W}$ ). The molecular weight of product was measured by GPC.

\section{Preparation of Casting Sample}

The casting sample was prepared from a chloroform solution. The solution of poly(XDS) was poured into a glass mold whose size $50(\mathrm{~L}) \times 10(\mathrm{~W}) \times 5(\mathrm{~T}) \mathrm{mm}$ in dark, and the solvent was dried at atmospheric pressure at room temperature in dark. The samples were dried under high reduced pressure (about $10^{-2}$ torr) at room temperature overnight until the sample weight kept constant.

\section{Polymer Characterization}

The number-average molecular weight $\left(M_{\mathrm{n}}\right)$, the weightaverage molecular weight $\left(M_{\mathrm{w}}\right)$ and the molecular weight distributions $\left(M_{\mathrm{w}} / M_{\mathrm{n}}\right)$ of the polymer were determined by GPC at $38^{\circ} \mathrm{C}$ in THF using a Tosoh GPC-8000 or 8020 series system. The molecular weight of polymers was calibrated with standard polystyrenes. ${ }^{1} \mathrm{H}$ and ${ }^{13} \mathrm{C}$ NMR spectra were recorded on a JEOL A-400 spectrometer in $\mathrm{CDCl}_{3}$ with tetramethylsilane as an internal standard at room temperature. Wide-angle $\mathrm{X}$-ray diffraction patterns in the range $2 \theta=10-40^{\circ}$ were measured on a Rigaku X-ray diffractometer Rint-Ultima with $\mathrm{Cu} \mathrm{K}{ }_{\alpha}$ radiation. MADLI-MS was measured on a Kratos PC Axima CFR with linear mode under the conditions of 2,5Dihydroxybenzoic acid (DHBA) as a matrix and AgTFA as a cationization reagent. 


\section{Thermal and Mechanical Properties}

Differential scanning calorimeter (DSC) measurement was carried out with a SEIKO Instruments Inc. DSC 6200 in nitrogen atmosphere at a heating rate of $10{ }^{\circ} \mathrm{C} / \mathrm{min}$. Thermogravimetric/Differential thermal analyses (TG/DTA) were carried out with a SEIKO Instruments Inc. TG/DTA 6200 in nitrogen atmosphere at a heating rate of $10^{\circ} \mathrm{C} / \mathrm{min}$ in the range from 25 to $500{ }^{\circ} \mathrm{C}$.

Dynamic mechanical measurement of poly(XDS) was performed by use of a SEIKO Instruments Inc. DMS 6100 in the shear mode operating at a frequency of $10 \mathrm{~Hz}$. The dimensions of the samples were $20(\mathrm{~L}) \times 8(\mathrm{~W}) \times 1(\mathrm{~T}) \mathrm{mm}$. Nitrogen gas was circulated in the environmental chamber to prevent degradation during the measurement. The shear storage modulus $\left(E^{\prime}\right)$, the shear loss modulus $\left(E^{\prime \prime}\right)$ and the loss factor $\left(\tan \delta\right.$ ) were obtained at a heating rate of $2{ }^{\circ} \mathrm{C} / \mathrm{min}$ in the range from -100 to $150{ }^{\circ} \mathrm{C}$.

\section{RESULTS AND DISCUSSION}

\section{Thermal Polymerization of XDS}

Previously, it was reported that cyclic disulfides underwent thermal polymerizations without initiators above the melting points, but they did not polymerize when the polymerizations were carried out below their melting points. ${ }^{44-46,54}$ Thermal polymerizations of XDS in bulk without any initiator at different temperature were examined and the results are listed in Table I. Although the thermal polymerization of XDS in bulk hardly proceeded below $60^{\circ} \mathrm{C}$, the polymerization of XDS was induced readily above $c a$. melting point of XDS to give a high molecular weight polymer, and the polymer yield increased with the rise of reaction temperature. The polymer obtained from the polymerization of highly purified XDS is referred to as poly(XDS) in this article.

\section{Structure of the Polymer}

The structure of the resulting polymer was checked by ${ }^{1} \mathrm{H}$ NMR spectroscopy. Figure 1 shows the ${ }^{1} \mathrm{H}$ NMR spectra of the polymer and XDS. In the spectrum of the polymer, the peaks based on the monomer disappeared and new peaks appeared at 3.67, 7.09-7.13 and 7.21-7.25 ppm based on the methylene and phenyl protons in the main chain of the polymer. On the other hand, signals based on the thiol proton which may be introduced at the chain end groups were not observed. The results indicates that the polymer consisted of repeating XDS units.

Table I. Bulk Polymerization of XDS for $2 \mathrm{~h}$ without Added Initiator ${ }^{\mathrm{a}}$

\begin{tabular}{ccccc}
\hline No. & Temp. $\left({ }^{\circ} \mathrm{C}\right)$ & Yield $(\%)$ & $M_{\mathrm{n}} \times 10^{-4}$ & $M_{\mathrm{w}} / M_{\mathrm{n}}$ \\
\hline 1 & 0 & - & - & - \\
2 & 40 & - & - & - \\
3 & 60 & trace & - & - \\
4 & 70 & 17 & 30.7 & 3.23 \\
5 & 80 & 25 & 19.6 & 2.44 \\
6 & 90 & 79 & 11.8 & 1.95 \\
\hline
\end{tabular}

${ }^{\mathrm{a}} M_{\mathrm{n}}$ and $M_{\mathrm{w}}$ were determined by GPC calibrated with standard polystyrenes.

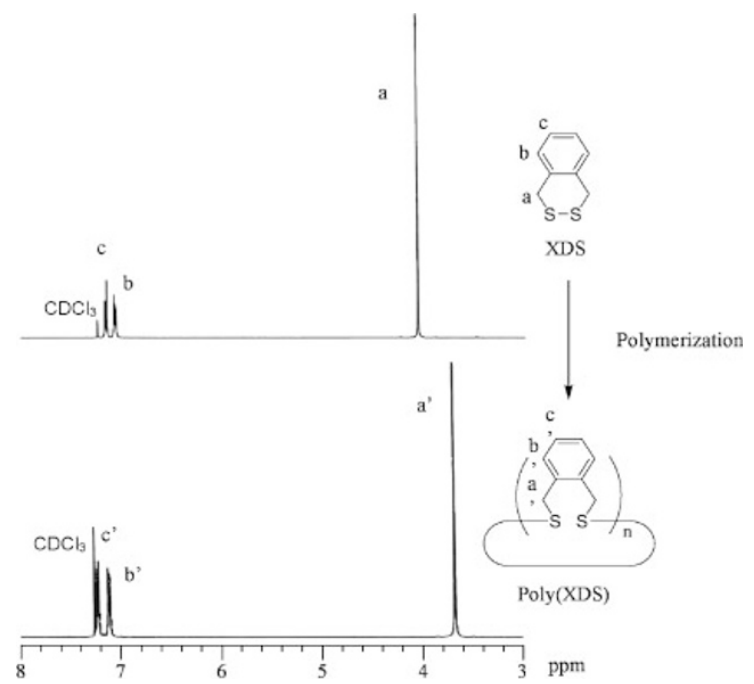

Figure 1. $400 \mathrm{MHz}{ }^{1} \mathrm{H}$ NMR spectra of $\mathrm{XDS}$ and poly(XDS) in $\mathrm{CDCl}_{3}$ at $25^{\circ} \mathrm{C}$.

Table II. Bulk Polymerization of XDS in the Presence of XDT

\begin{tabular}{ccccccc}
\hline No. & $\begin{array}{c}{[\mathrm{XDT}] /[\mathrm{XDS}]} \\
\times 10^{2}\end{array}$ & $\begin{array}{c}\text { Time } \\
(\mathrm{h})\end{array}$ & $\begin{array}{c}\text { Temp. } \\
\left({ }^{\circ} \mathrm{C}\right)\end{array}$ & $\begin{array}{c}\text { Yield } \\
(\%)\end{array}$ & $M_{\mathrm{n}} \times 10^{-4}$ & $M_{\mathrm{w}} / M_{\mathrm{n}}$ \\
\hline 7 & 1 & 2 & 80 & 2.1 & 9.2 & 1.63 \\
8 & 2 & 48 & 90 & 19.6 & 1.6 & 2.51 \\
\hline
\end{tabular}

a $M_{\mathrm{n}}$ and $M_{\mathrm{w}}$ were determined by GPC calibrated with standard polystyrenes.

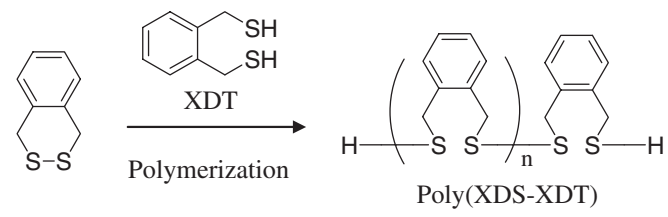

Scheme 2. Synthesis of linear polymer.

To clarify further the structure of the poly(XDS), thermal polymerization of XDS was examined in the presence of $\alpha, \alpha^{\prime}$ mercapto-o-xylene (XDT). The results are listed in Table II. The polymer yield and molecular weight of polymers became low as compared to the polymerization in the absence of XDT. If XDT acts as a strong chain-transfer agent, this polymerization will give a liner poly(XDS-XDT) having dithiol groups at the chain end as illustrated in Scheme 2.

The ${ }^{1} \mathrm{H}$ NMR spectra of poly(XDS-XDT) and poly(XDS) are shown in Figure 2. The triplet peaks based on the thiol proton were observed at $1.76 \mathrm{ppm}$ in addition to the methylene protons in the main chain, but this peak was not observed on the spectrum of poly(XDS). Namely, poly(XDS-XDT) is clearly a liner polymer, and poly(XDS) was presumed to be a cyclic structure.

Since it is difficult to confirm clearly the cyclic structure of the poly(XDS) by NMR spectroscopy, the MALDI-MS of the polymer was measured to confirm the structure. The charts are shown in Figure 3. The observed peaks were in good agree- 

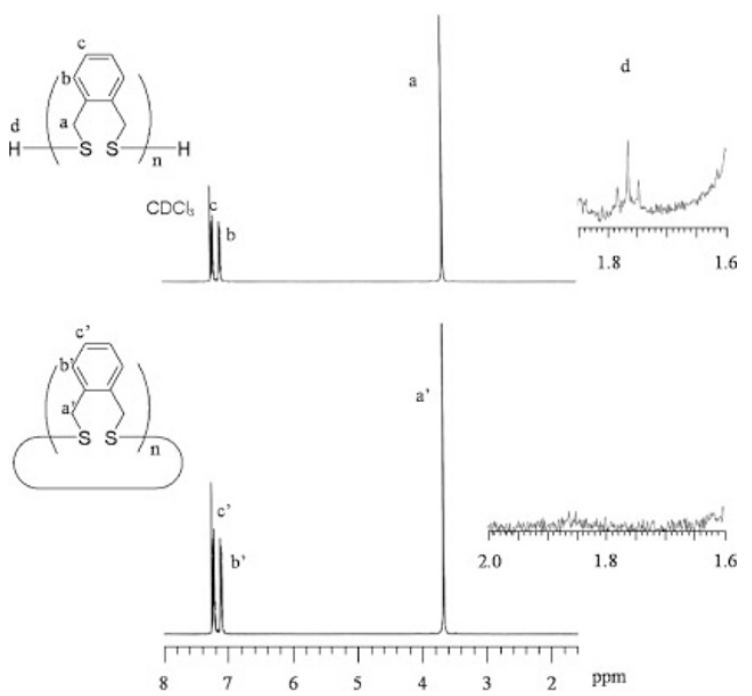

Figure 2. ${ }^{1} \mathrm{H} 400 \mathrm{MHz}{ }^{1} \mathrm{H}$ NMR spectra of poly(XDS-XDT) and poly(XDS) in $\mathrm{CDCl}_{3}$ at room temperature. $\mathrm{Y}$-axis is $\times 100$ times in the expanded spectra at $1.6-2.0 \mathrm{ppm}$.

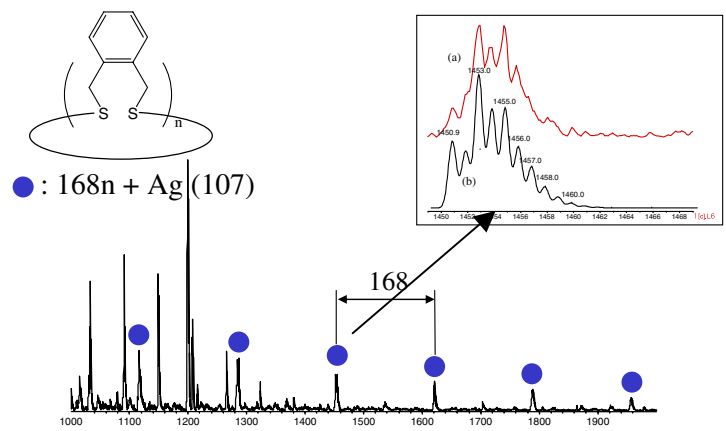

Figure 3. MALDI-MS charts of poly(XDS) (GPC data; $M_{\mathrm{n}}=2.6 \times 10^{5}, M_{\mathrm{w}}=$ $\left.5.1 \times 10^{5}, M_{\mathrm{w}} / M_{\mathrm{n}}=1.92\right)$, Matrix: 2,5-Dihydroxybenzoic acid, Cationization reagent: AgTFA, (a) is observed chart and (b) theory chart taking into isotopic effect.

ment with the cyclic poly(XDS) with repetition of $168 \mathrm{Da}$ intervals. The peaks expanded at near $\mathrm{m} / z 1453$ are also shown in Figure 3(a) and 3(b). The isotope distribution of a measured ion accords with the theory value of the cyclic structure $\left[\left(\mathrm{C}_{8} \mathrm{H}_{8} \mathrm{~S}_{2}\right)_{8}+\mathrm{Ag}\right]$. Namely, the cyclic structure was confirmed by the detected ion.

\section{Polymerization of XDS in the Presence of Cyclic Poly(oxy- ethylene)}

Taking the polymerization mechanism of cyclic disulfides into the consideration, it will be possible to synthesize an interlocking product consisting of two different ring polymers from thermal polymerization of XDS in the presence of another cyclic polymer. For this purpose, thermal polymerization of $\mathrm{XDS}$ was conducted at $90^{\circ} \mathrm{C}$ for $15 \mathrm{~h}$ in the presence of cyclic poly(oxyethylene) (CPO). The results are listed in Table III. After the polymerization, the products were extracted with an excess of methanol to remove the non-interlocking CPO, because CPO dissolves easily in methanol.

\begin{tabular}{ccccc}
\multicolumn{5}{c}{$\begin{array}{c}\text { Table III. } \\
\text { in the Presence of } \mathrm{CPO} \text { at } 90^{\circ} \mathrm{C} \text { for } 15 \mathrm{~h}^{\mathrm{a}}\end{array}$} \\
\hline No. & {$[\mathrm{CPO}] /[\mathrm{XDS}] \times 10^{2}$} & Yield $(\%)$ & $M_{\mathrm{n}} \times 10^{-4}$ & $M_{\mathrm{w}} / M_{\mathrm{n}}$ \\
\hline 9 & 2.7 & 13.8 & 40.1 & 2.23 \\
\hline
\end{tabular}

${ }^{a} M_{\mathrm{n}}$ and $M_{\mathrm{w}}$ were determined by GPC calibrated with standard polystyrenes.

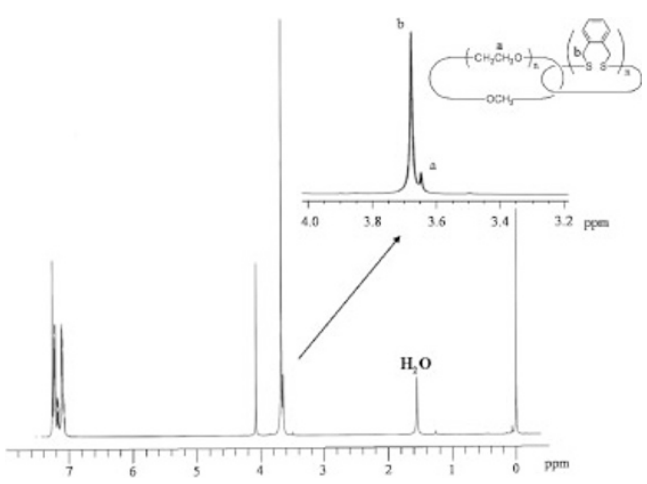

Figure 4. $400 \mathrm{MHz}{ }^{1} \mathrm{H}$ NMR spectrum of poly(XDS)-CPO in $\mathrm{CDCl}_{3}$ at room temperature.

(a)

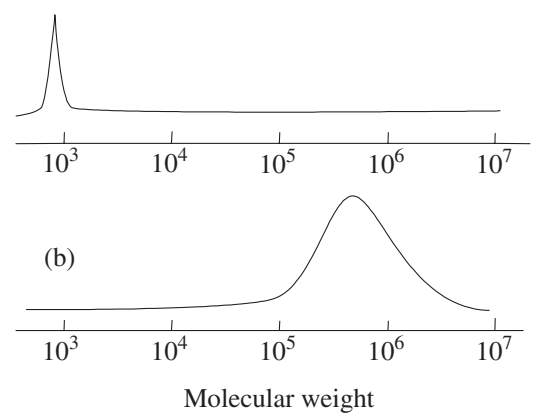

Figure 5. GPC elution curves of (a) CPO $\left(M_{\mathrm{w}}=825, M_{\mathrm{w}} / M_{\mathrm{n}}=1.01\right)$, and (b) poly(XDS)-CPO $\left(M_{\mathrm{w}}=40.1 \times 10^{-4}, M_{\mathrm{w}} / M_{\mathrm{n}}=2.23\right)$ in THF.

The ${ }^{1} \mathrm{H}$ NMR spectrum of the reaction product is shown in Figure 4. Not only signals at 3.67, 7.09-7.13 and 7.21$7.25 \mathrm{ppm}$ based on methylene and phenyl protons in main chain of poly(XDS), but also the signal based on methylene protons in main chain of $\mathrm{CPO}$ were detected at $3.7 \mathrm{ppm}$. Although these signals based on both polymers were observed in ${ }^{1} \mathrm{H}$ NMR spectrum of the polymeric product, these may be due to only mixture of poly(XDS) and CPO.

Figure 5 shows GPC elution curves of the polymeric product and CPO. The GPC elution curve of CPO exhibited one large peak. On the other hand, in the GPC elution curve of the polymeric product, no peak corresponding to the molecular weight of CPO was observed. This indicates that the polymeric product obtained from thermal polymerization of XDS in the presence of CPO maybe include a polycatenane structure entangled by cyclic poly(XDS) and CPO each other. The yield of the polycatenane estimated by the NMR spectrum of the product was also very low like only $0.05 \%$. Such very low yield was reported by Wasermann on the [2] catenane formation. ${ }^{27}$ 


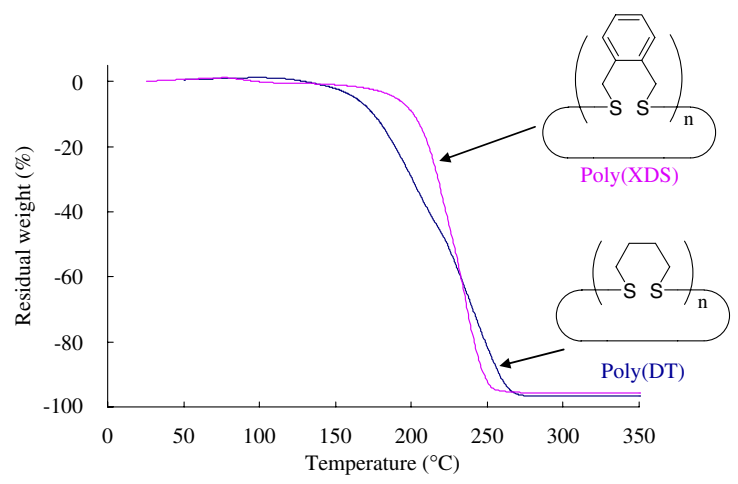

Figure 6. TG curves of poly(XDS) and poly(DT) at a heating rate of $10^{\circ} \mathrm{C} /$ $\min$ in nitrogen atmosphere.
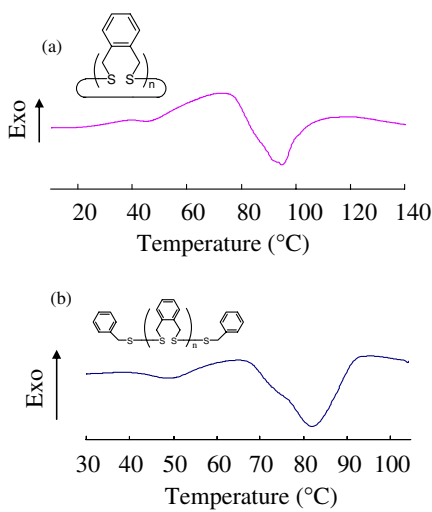

Figure 7. DSC curve of (a) poly(XDS) and (b) linear poly(XDS) at a heating rate of $10^{\circ} \mathrm{C} / \mathrm{min}$. under nitrogen atmosphere.

\section{Thermal Poperties of Poly(XDS)}

The thermal analyses of poly(XDS) and poly(DT) were examined in detail. The TG/DTA charts are shown in Figure 6. The initial decomposition temperature of the sample $\left(T_{\text {ini }}\right)$ is defined as the temperature of $5 \%$ weight loss determined by TG/DTA. The $T_{\text {ini }}$ of poly(XDS) was found to be $c a \cdot 190^{\circ} \mathrm{C}$ and that of poly(DT) was $c a .140{ }^{\circ} \mathrm{C} .{ }^{46}$

The $T_{\text {ini }}$ of poly(XDS) was higher than of poly(DT). After the initial decomposition, the residual weights of both polymers rapidly decreased. The results of DSC measurement are shown in Figure 7. The glass transition temperature $\left(T_{\mathrm{g}}\right)$ and the melting point $\left(T_{\mathrm{m}}\right)$ of poly(XDS) were $c a .39^{\circ} \mathrm{C}$ and ca. $95^{\circ} \mathrm{C}$, respectively. For linear poly(XDS) obtained from polymerization of XDS in the presence of dibenzyldisulfide these values were $40{ }^{\circ} \mathrm{C}$ and $82^{\circ} \mathrm{C}$. Since the $T_{\mathrm{g}}$ and $T_{\mathrm{m}}$ of poly(DT) were reported to be $c a .-55^{\circ} \mathrm{C}$ and $c a .42^{\circ} \mathrm{C}$, respectively, ${ }^{46}$ poly(XDS) is more rigid than poly(DT). This may be related to the presence of benzene ring in the main chain.

\section{Wide-angle X-ray Diffraction Analysis}

Wide-angle X-ray diffraction analysis of poly(XDS) and poly(DT) were performed, and the patterns are shown in Figure 8 . The crystallinity of poly(XDS) was calculated to be

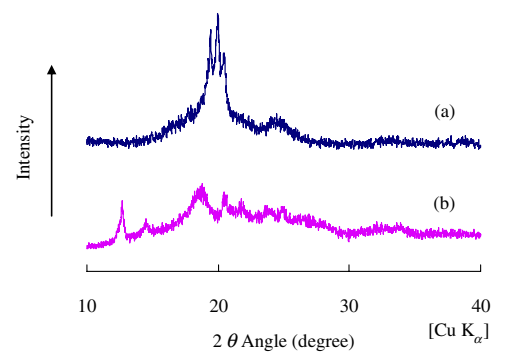

Figure 8. Wide-angle X-ray diffraction patterns of (a) poly(DT) and (b) poly(XDS).

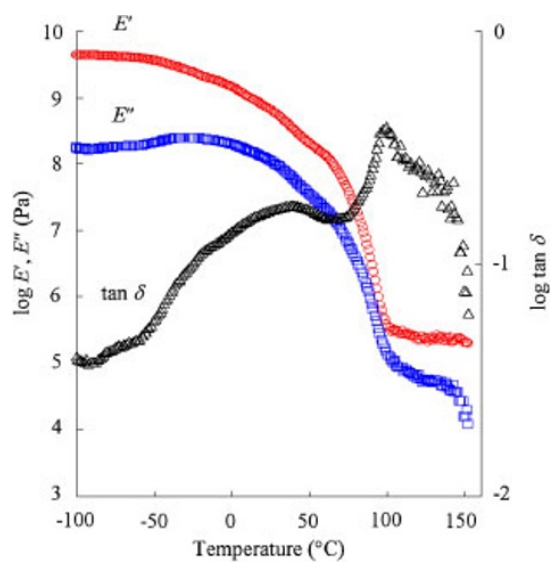

Figure 9. Temperature dependence of $E^{\prime}, E^{\prime \prime}$ and $\tan \delta$ for poly(XDS) at a frequency of $10 \mathrm{~Hz}$.

ca. $7 \%$ from the area ratio of the crystalline region to the total regions. In the poly(DT), it was ca. 30\%. Although the difference in the crystallization mechanism for both polymers is not clear, benzene rings in the main chain may change crystallization.

\section{Mechanical Properties of the Polymers}

Mechanical properties would give useful information about the polymer structure as reported previously. ${ }^{46}$ So temperature dependences of storage modulus $\left(E^{\prime}\right)$, loss modulus $\left(E^{\prime \prime}\right)$ and $\tan \delta$ for poly(XDS) were investigated, and the results are shown in Figure 9. The $M_{\mathrm{n}}$ of poly(XDS) was determined by GPC to be $8.4 \times 10^{4}$. Above the temperature of $c a .39^{\circ} \mathrm{C}$, $E^{\prime}$ and $E^{\prime \prime}$ values decreased significantly, and $\tan \delta$ values temporarily increased, which is in good agreement with the glass transition temperature of poly(XDS) determined by DSC. Interestingly, $E^{\prime}$ and $E^{\prime \prime}$ were constant above $100^{\circ} \mathrm{C}$, i.e., poly(XDS) showed a rubbery plateau even though the polymer is molten state. Taking the unusual behavior of poly(XDS) at molten state into consideration, the observed dynamic viscoelasticity behavior of poly(XDS) above the melting point of the polymer may be attributed to the catenane structure.

\section{Solubility of the Polymer}

In the dissolution process of poly(XDS), the polymer first swells like a gel and the volume of poly(XDS) expands for a 


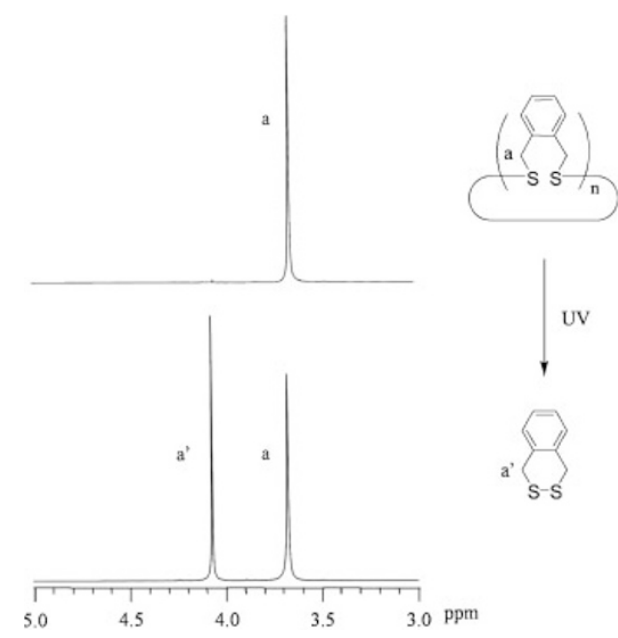

Figure 10. $400 \mathrm{MHz}{ }^{1} \mathrm{H}$ NMR spectra of poly(XDS) before and after decomposition in $\mathrm{CDCl}_{3}$ at room temperature.

long time, and eventually it dissolves in $\mathrm{CHCl}_{3}$ and THF. On the other hand, poly(XDS-XDT) with a similar molecular weight dissolved instantly in THF and $\mathrm{CHCl}_{3}$, and a gel like state during dissolution process was not observed. The difference in dissolution process between two polymers suggests that poly(XDS) contains a spatially linked structure.

\section{Degradation of the Polymer}

On the thermal decomposition of poly(XDS) by TG analysis, it was observed that rapid weight loss was observed at the initial stage of the decomposition. After the decomposition of poly(XDS) under UV irradiation in chloroform at room temperature using a high-pressure $\mathrm{Hg}$ lamp, peaks of the polymer and the monomer were only observed in the ${ }^{1} \mathrm{H}$ NMR spectrum of the reaction product of poly(XDS), as shown in Figure 10. This suggests that depolymerization of poly(XDS) finally gives XDS.

This indicates that the molecular weight of non-interlocking cyclic polymers which are component of polycatenane is able to be estimated. If the polymer consists of cyclic polymers bearing similar molecular weights, the degradation of the polymer will give a non-interlocking cyclic polymer with similar molecular weight as illustrated in Scheme 3. In the decomposition of the poly(XDS), the molecular weight of the polymer estimated by GPC should rapidly decrease at the early stage of the degradation reaction, there are the interlocked structural entanglements. The $\mathrm{S}-\mathrm{S}$ bonds should be cleaved by UV irradiation. Actually, similar decomposition behavior was reported in the case of poly(DT) ${ }^{45,46}$ To elucidate the point for the poly(XDS), the photodecompositions were carried out under UV irradiation in THF at room temperature using a highpressure $\mathrm{Hg}$ lamp, and the results are shown in Figure 11. The molecular weight decreased remarkably at the early stage of the decomposition. After that, the molecular weights were constant even for a prolonged irradiation time, which is similar to that of the poly(DT) assumed to consist of polycatenane structures.

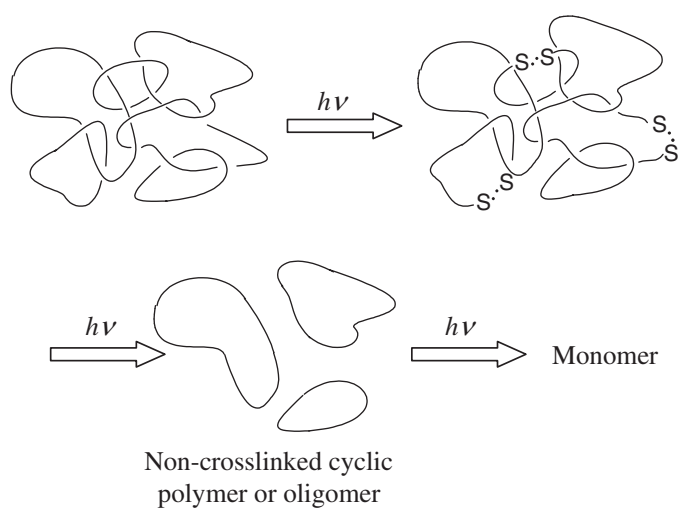

Scheme 3. Illustration for Photodecomposition Process of Polycatenane Structure.

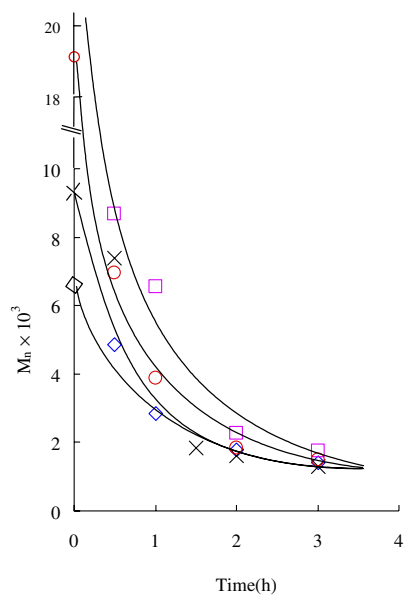

Figure 11. Photodecomposition behaviors of poly(XDS) in THF $(0.02 \mathrm{wt} \%)$ with a high-pressure $\mathrm{Hg}$ lamp at room temperature.

Figure 12 shows the GPC elution curves of the photodecomposition products of poly(XDS). From the GPC elution curves, it was found that the peak of the high molecular weight region disappeared rapidly at the early stage of the decomposition. After that, the peak converged on a certain low molecular weight $\left(c a .2 .0 \times 10^{3}\right)$. The converged region is assumed to be a molecular weight of a non-linked cyclic poly(XDS). On the basis of the results obtained, it would be concluded that polycatenane structure is formed by the bulk polymerization of XDS.

The formation of polycatenane from the ring openingpolymerization of cyclic disulfides may be explanation by the followings. The polymerization conditions of cyclic disulfides are consider to prefer intermolecular reaction rather than intramolecular reaction. Intermolecular reaction is typical propagation process in the polymerization, leading to the formation of linear polymers. The cyclic polymer can be obtained mainly by a back biting reaction. It does not depend on concentration of monomer. Thus the bulk polymerization prefers to form cyclic ring rather than solution polymerization. In addition, chain penetration in cyclic polymer is also preferable in bulk polymerization, since many formed cyclic 


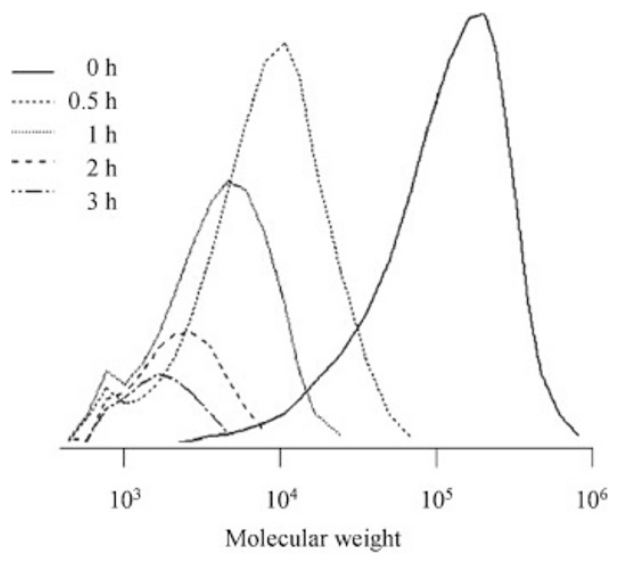

Figure 12. GPC elution curves for the photodecomposition products of poly(XDS) in THF (0.02 wt \%) with a high-pressure Hg lamp at $25^{\circ} \mathrm{C}$.

rings are present in the bulk polymerization system. Moreover, the formed ring is able to attack again the active chain end to give active chain, and such polymer is also possible to induce back biting reaction to form a polycatenane structure.

\section{CONCLUSION}

The polymerization of highly purified XDS proceeded easily at reaction temperatures above the melting point of XDS giving high molecular weight polymer. From the structural analysis of poly(XDS), the polymer was found to have cyclic structure, in contrast to that linear polymer obtained from the polymerization of XDS in the presence of thiol compounds such as XDT.

TG Analysis and DSC measurement of poly(XDS) indicate that the polymer is more thermal stable in comparison to poly(DT). Wide-angle X-ray diffraction analysis showed that the crystallinity of poly(XDS) was lower than that of poly(DT).

Dynamic viscoelastic measurement demonstrated that the poly(XDS) showed a rubbery plateau in the melt state of the polymer even though the polymer has no crosslinking structure. A difference in solubility between poly(XDS) and poly(XDSXDT) for $\mathrm{CHCl}_{3}$ or THF was also observed. Thus, we would like to conclude that poly(XDS) obtained from thermal polymerization of XDS includes a polycatenane structure, and the molecular weight of non-interlocking cyclic polymers was estimated to be $c a .2 .0 \times 10^{3}$ from decomposition of the original polymer.

Acknowledgment. We grateful acknowledge to Professor Dr. R. Arakawa of Kansai University for a measurement of MALDI-MS spectra of the polymers and for his helpful comments on the information about the structure of the polymer.

Received: September 16, 2008

Accepted: October 14, 2008

Published: December 5, 2008

\section{REFERENCES}

1. H. W. Gibson, M. C. Bheda, and P. T. Engan, Prog. Polym. Sci., 19, 843 (1994).

2. H. W. Gibson, "Large Ring Molecules," J. A. Semlyen Ed., John Wiley and Sons, New York, 1996, chap. 6, pp 191-262.

3. C. Gong and H. M. Gibson, Opin Solid St. Mater. Sci., 2, 647 (1997).

4. F. M. Raymo and J. F. Stoddard, Chem. Rev., 99, 1643 (1999).

5. C. Gong and H. M. Gibson, "Molecular Catenanes, Rotaxanes and Knot," J.-P. Sauvage and C. O. Dietrich-Buchecker, Eds., WileyVCH, Weinheim, 1999, Chap. 11, pp 277-321.

6. H. Mahan and H. M. Gibson, "Cyclic Polymers," 2nd ed., J. A. Semlyen Ed., Kluwer Publisher, Dordrecht, 2000, pp 415-560.

7. I. N. Hubin and D. H. Busch, Coord. Chem. Rev., 200-202, 5 (2000).

8. I. G. Panova and I. N. Topchieva, Russ. Chem. Rev., 70, 23 (2001).

9. F. Huang and H. M. Gibson, Prog. Polym. Sci., 30, 982 (2005).

10. A. Harada, A. Hashidzume, and T. Takashima, Adv. Polym. Sci., 201, 1-43 (2006).

11. T. Takata, Polym. J., 38, 1 (2006).

12. P. Rempp, C. Strazielle and P. Lutz, "Encyclopedia of Polymer Science and Engineering," 2nd ed., J. I. Kroschwitz Ed., Wiley, New York, 1987, Vol. 9, pp 183-195.

13. Y. Ederle, K. S. Naraghi, and P. J. Lutz, "Synthesis of Polymers," A.-D. Schlüter, Ed., Wiley-VCH, Weinheim, 1999, Chap. 19.

14. K. Iwata, Macromolecules, 18, 115 (1985).

15. C. W. Bielawski, D. Benitez, and R. H. Grubbs, Science, 297, 2041 (2002).

16. Y. Tezuka and H. Oike, Prog. Polym. Sci., 27, 1069 (2002).

17. Y. Tezuka and R. Komiya, Macromolecules, 35, 8667 (2002).

18. H. R. Kricheldorf, S.-R. Lee, and S. Bush, Macromolecules, 29, 1375 (1996).

19. H. R. Kricheldorf, N. Lomadze, and G. Schwarz, Macromolecules, 40, 4818 (2007).

20. H. R. Kricheldorf, N. Lomadze, and G. Schwarz, Macromolecules, 40, 4859 (2007).

21. M. Garaleh, C. Polefka, G. Schwarz, and H. R. Kricheldorf, Macromol. Chem. Phys., 208, 747 (2007).

22. H. R. Kricheldorf, K. Bornhorst, and G. Schwarz, Macromolecules, 40, 199 (2007).

23. H. R. Kricheldorf, M. A. Masri, and G. J. Schwarz, Macromol. Sci., Part A: Pure and Appl. Chem., 43, 1 (2006).

24. H. Iatrou, N. Hadjichristidis, G. Meier, H. Frielinghaus, and M. Monkenbusch, Macromolecules, 35, 5426 (2002).

25. L. Rique-Lurbet, M. Schappacher, and A. Deffieux, Macromolecules, 27, 6318 (1994).

26. W. Lee, H. Lee, H. C. Lee, D. Cho, T. Chang, A. Gorbunov, and J. Roovers, Macromolecules, 35, 529 (2002).

27. E. Wasserman, J. Am. Chem. Soc., 82, 4433 (1960).

28. D. M. Walba, Tetrahedron, 41, 3161 (1985).

29. J.-P. Sauvage, Acc. Chem. Res., 31, 611 (1998).

30. P. R. Ashton, T. T. Goodnow, A. E. Kaifer, M. V. Reddington, A. M. Z. Slawin, N. Spencer, J. F. Stoddart, C. Vicent, and D. J. Williams, Angew. Chem., Int. Ed. Engl., 28, 1396 (1989).

31. D. B. Amabilino, P. R. Ashton, V. Balzani, S. E. Boyd, A. Credi, J. Y. Lee, S. Menzer, J. F. Stoddart, M. Venturi, and D. J. Williams, J. Am. Chem. Soc., 120, 4295 (1998).

32. M. Fujita, Acc. Chem. Res., 32, 53 (1999).

33. L. Wang, M. O. Vysotsky, A. Bogdan, M. Bolte, and V. Böhmer, Science, 304, 1312 (2004).

34. K. S. Chichak, S. J. Cantrill, A. R. Pease, S.-H. Chiu, G. W. V. Cave, J. L. Atwood, and J. F. Stoddart, Science, 304, 1308 (2004).

35. F. M. Raymo and J. F. Stoddart, Chem. Rev., 99, 1643 (1999).

36. C. A. Fustin, G. J. Clarkson, D. A. Leigh, F. Van Hoof, A. M. Jonas, and C. Bailly, Macromolecules, 37, 7884 (2004).

37. H. W. Gibson, D. S. Negvekar, N. Ymamaguchi, S. Bhattacharjee, H. Wang, M. J. Vergne, J. Matthew, and D. Hercules, Macromolecules, 37, 7514 (2004). 
38. N. Watanabe, Y. Ikari, N. Kihara, and T. Takata, Macromolecules, 37, 6663 (2004).

39. F. O. Davis and E. M. Fettes, J. Am. Chem. Soc., 70, 2611 (1948).

40. A. V. Tobolsky, I. Leonard, and G. P. Roeser, J. Polym. Sci., 3, 604 (1948).

41. J. G. Affleck and G. Dougherty, J. Org. Chem., 15, 865 (1950).

42. R. B. Whitney and M. Calvin, J. Chem. Phys., 23, 1750 (1955).

43. K. Kishore and K. Ganesh, Adv. Polym. Sci., 121, 81-121 (1995).

44. K. Endo, T. Shiroi, and N. Murata, J. Soc. Rub. Ind. Jpn., 73, 392 (2000).

45. R. Arakawa, T. Watanabe, T. Fukuo, and K. Endo, J. Polym. Sci., Part A: Polym. Chem., 38, 4403 (2000).

46. K. Endo, T. Shiroi, N. Murata, G. Kojima, and T. Yamanaka,
Macromolecules, 37, 3143 (2004).

47. F. Vögtle, M. Zuber, and R. G. Lichtenthaler, Chem. Br., 106, 717 (1973).

48. B. Sket and M. Zupan, J. Org. Chem., 51, 929 (1986).

49. J. A. W. Verhagen, D. D. Ellis, M. Lutz, A. L. Spek, and E. Bouwman, J. Chem. Soc., Dalton Trans., 1275 (2002).

50. D. N. Harpp, R. A. Smith, and K. Steliou, J. Org. Chem., 46, 2072 (1981).

51. R. Singh and G. M. Whitesides, J. Am. Chem. Soc., 112, 6304 (1990).

52. R. Sato, J. Soc. Rub. Ind. Jpn., 65, 149 (1992).

53. G.-E. Yu, P. Sinnathamby, C. Price, and C. Booth, Chem. Commun., 31 (1996).

54. R. C. Thomas and L. J. Reed, J. Am. Chem. Soc., 78, 6148 (1956). 